\title{
Use of multi-model ensembles from global climate models for assessment of climate change impacts
}

\author{
Mikhail A. Semenov*, Pierre Stratonovitch \\ Centre for Mathematical and Computational Biology, Rothamsted Research, Harpenden, Hertfordshire AL5 2JQ, UK
}

\begin{abstract}
Multi-model ensembles of climate predictions constructed by running several global climate models for a common set of experiments are available for impact assessment of climate change. Multi-model ensembles emphasize the uncertainty in climate predictions resulting from structural differences in the global climate models as well as uncertainty due to variations in initial conditions or model parameterisations. This paper describes a methodology of using multi-model ensembles from global climate models for impact assessments which require local-scale climate scenarios. The approach is based on the use of a weather generator capable of generating the localscale daily climate scenarios used as an input by many process-based impact models. A new version of the LARS-WG weather generator, described in the paper, incorporates climate predictions from 15 climate models from the multi-model ensemble used in the IPCC Fourth Assessment Report (AR4). The use of the AR4 multi-model ensemble allows assessment of the range of uncertainty in the impacts of climate change resulting from the uncertainty in predications of climate. As an example, the impact of climate change on the probability of heat stress during flowering of wheat, which can result in significant yield losses, was assessed using local-scale climate scenarios in conjunction with a wheat simulation model at 4 European locations. The exploitation of much larger perturbed physics ensembles is also discussed.
\end{abstract}

KEY WORDS: Weather generator · Probabilistic prediction · Uncertainty · IPCC AR4 · LARS-WG Resale or republication not permitted without written consent of the publisher

\section{INTRODUCTION}

The IPCC Fourth Assessment Report (AR4) was based on large data sets of projections of future climate produced by 18 modelling groups worldwide, who performed a set of coordinated climate experiments in which several global climate models (GCMs) were run for a common set of experiments and various emissions scenarios (Solomon et al. 2007). These data sets are freely available from the IPCC Data Distribution Centre (www.ipcc-data.org) and can be used by the research community to assess the impact of changing climate on various systems of interest, including impacts on agricultural crops and natural ecosystems, biodiversity and plant diseases. Multi-model ensembles emphasize the uncertainty in climate predictions resulting from structural differences in the global climate models as well as uncertainty in variations of initial condi- tions or model parameterisations. These uncertainties in climate predictions need to be accounted and translated into uncertainty in impacts.

However, the direct use of climate predictions from the AR4 multi-model ensemble in conjunction with process-based impact models could be difficult, because these predictions are typically available as monthly means or changes in monthly means of climatic variables, but process-based models depend on daily time-series of weather as one of their main inputs. Even when daily output is available from GCMs, the coarse spatial resolution of GCMs and large uncertainty in their output on a daily scale, particularly for precipitation, means that the output is not appropriate for direct use with process-based models and analysis of extreme events (Semenov 2007). Despite an increasing ability of GCMs to successfully model present-day climate, the latest generation of 
GCMs still has serious difficulties in reproducing daily precipitation and temperature (Trigo \& Palutikof 2001). Output from GCMs requires application of various downscaling techniques (Barrow et al. 1996, Bardossy 1997, Wilby et al. 1998, Mearns et al. 1999, Murphy 1999, Salon et al. 2008). One of the downscaling techniques to create daily site-specific climate scenarios makes use of a stochastic weather generator (WG; Wilks 1992, Barrow \& Semenov 1995, Wilks \& Wilby 1999, Semenov 2007). A WG is a model which, after calibration of site parameters with observed weather at that site, is capable of simulating synthetic time-series of daily weather that are statistically similar to observed weather (Richardson \& Wright 1984, Wilks \& Wilby 1999). By altering the parameters of the WG using changes in climate predicted from GCMs, it is possible to generate synthetic daily weather for the future. WGs are extensively used to generate long time-series weather data suitable for the assessment of agricultural and hydrological risk (Mavromatis \& Hansen 2001); to provide the means of extending the simulation of daily weather to unobserved locations by spatially interpolating parameters of WG (Semenov \& Brooks 1999); and to serve as a computationally inexpensive tool to produce daily site-specific climate scenarios for impact assessments of climate change (Mearns et al. 1999, Dubrovsky et al. 2004, Evans et al. 2008, Semenov 2009, Semenov \& Halford 2009). The use of WGs in climate change studies allows exploration of the effect of changes in mean climate as well as changes in climatic variability and extreme events (Porter \& Semenov 2005). The latter could be critically important for analysis of complex non-linear systems, including biological systems, that incorporate non-linear interactions between system components and the surrounding environment (Semenov \& Porter 1995, Moot et al. 1996, Mearns et al. 1997). A non-linear model can potentially produce very different responses depending on whether or not changes in climatic variability are incorporated into climate scenarios (Porter \& Semenov 1999, 2005).

The objective of the present study is to describe how climate predictions in the form of a multi-model ensemble can be used for impact assessments which require local-scale climate scenarios. The approach is based on the LARS-WG weather generator (Semenov 2007, 2008b). A new version of LARS-WG is described, which incorporates predictions from the AR4 multimodel ensemble (Table 1). Given site parameters derived from observed daily weather, WG can generate local-scale daily climate scenarios for the future at any location in the world consistent with the AR4 climate predictions. By treating each GCM prediction from the AR4 ensemble as an equally possible evolution of climate, we can explore the uncertainty in im- pact assessment resulting from the uncertainty in climate predictions. As an illustration, the local-scale climate scenarios based on the IPCC AR4 multi-model ensemble were generated and used to assess the changes in probability of heat stress around flowering for wheat at several locations in Europe, an event which can result in a large number of sterile grains and substantially reduce the crop yield (Wheeler et al. 2000).

\section{METHODS}

\subsection{AR4 multi-model ensemble of climate predictions}

A new version of the LARS-WG incorporates predictions from 15 GCMs used in the IPCC AR4 (Solomon et al. 2007). Table 1 summarises important features of these GCMs, including grid resolution, available Special Report on Emissions Scenarios (SRES) emissions scenarios (Nakicenovic \& Swart 2000) and their reference time periods for climate predictions. Climate models are referred to in LARS-WG by their acronyms used in AR4 (Table 1). For most of the GCMs from the AR4 multi-model ensemble, climate predictions are available for the SRES emissions scenarios SRB1, SRA1B and SRA2. The key assumptions of the SRES emissions scenarios and corresponding increases in $\mathrm{CO}_{2}$ concentrations are given in Table 2 (Nakicenovic \& Swart 2000). All of these GCMs are coupled atmosphere-ocean models and most of them were run for the period 1960-2100. The outputs from these GCMs are available as monthly means of climatic variables, including precipitation, maximum and minimum temperatures and radiation for the baseline period corresponding to 1960-1990 and the periods 2011-2030, 2046-2065 and 2081-2100. Some of the climate centres made available 2 independent runs of their GCMs, which differed in their initial conditions and/or model parameterization. Only the output from the first run for each GCM has been incorporated into LARS-WG.

There is a growing confidence that GCMs provide a realistic quantitative prediction of climate change, especially at the continental scale (Solomon et al. 2007). These models are routinely assessed by comparing their simulations with observed data of the atmosphere, ocean and land surface. GCMs are regularly evaluated through multi-model intercomparisions (Covey et al. 2003, Déqué et al. 2007, Huebener et al. 2007, Jacob et al. 2007). Some climate models have been used at shorter time scales for predicting weather (over days or weeks) or seasonal forecasting (over months) (Palmer et al. 2004, 2008). GCMs have demonstrated skills in simulating circulation patterns and seasonal and interannual variability (Palmer et al. 2005, Doblas-Reyes et al. 


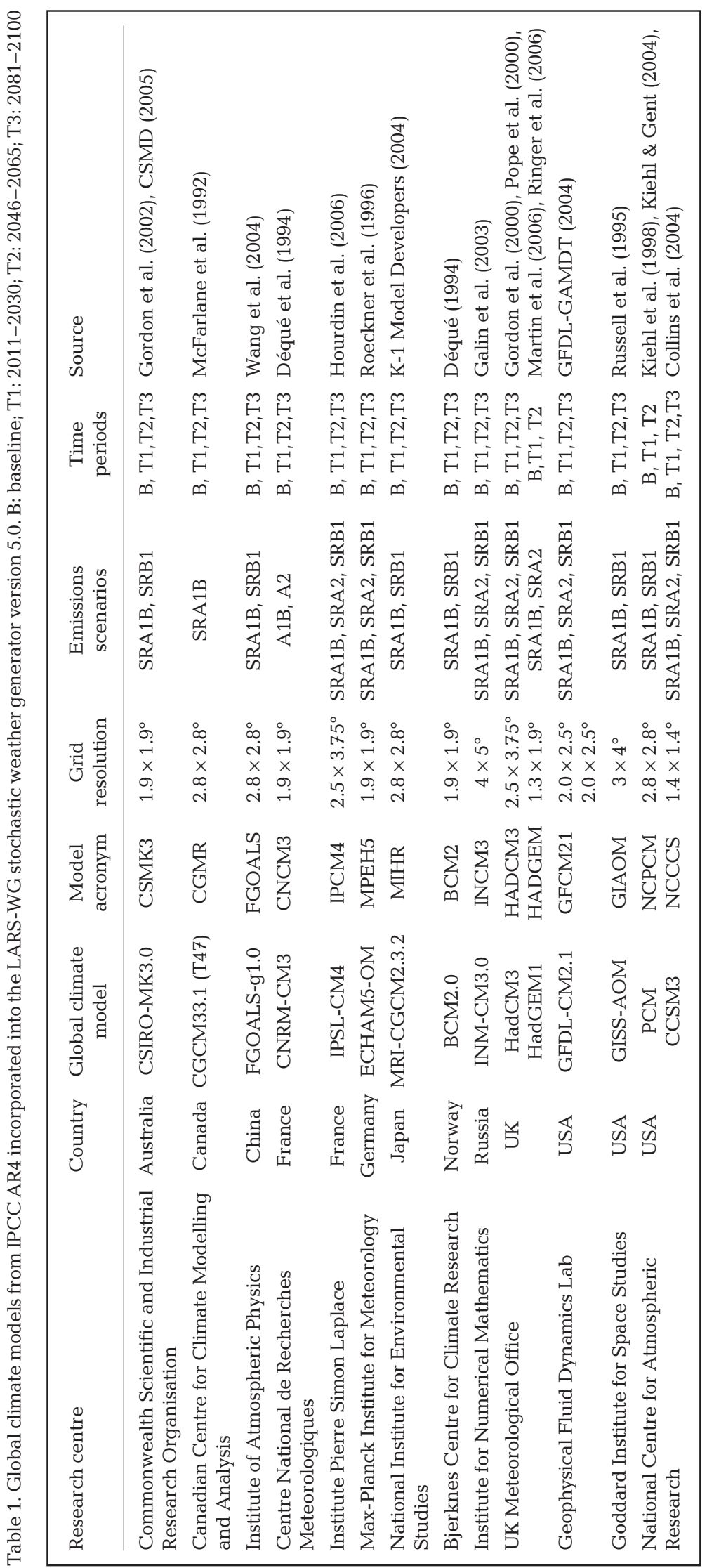

2006). The ability of GCMs to reproduce these and other important climate attributes increases our confidence that they incorporate the key physical processes critical for the modelling of climate change. In addition, GCMs have been used to simulate paleoclimate, including the Last Glacial Maximum that occurred about $21000 \mathrm{yr}$ ago, and were able to successfully reproduce features such as the magnitude and broad-scale pattern of oceanic cooling during the last ice age (Ramstein et al. 2007, Otto-Bliesner et al. 2009).

However, the coarse spatial resolution of GCMs results in significant errors and large uncertainty in their output at a local scale, particularly for precipitation. The source of errors is related to the fact that many small-scale processes cannot be represented explicitly in climate models, and must be approximated. This happens because of constraints in computing power, limitations in our understanding of smallscale processes and the lack of detailed observations required for validation. Various downscaling techniques have been developed to underpin studies on regional and local-scale climate change, including dynamic downscaling by regional climate models (Giorgi \& Mearns 1991, Murphy 1999), statistical downscaling (Hewitson \& Crane 1996, Wilby et al. 1998, Murphy 1999) and WGs (Wilks 1992, Semenov \& Barrow 1997). In this paper we explore the methodology based on a WG.

\subsection{Revision of LARS-WG}

LARS-WG is a stochastic WG based on the series approach (Racsko et al. 1991), with a detailed description given in Semenov (2007). LARS-WG produces synthetic daily time series of maximum and minimum temperatures, precipitation and solar radiation. The WG uses observed daily weather for a given site to compute a set of parameters for probability distributions of weather variables as well as correlations between them. This set of parameters is used to generate synthetic weather time series of arbitrary length by randomly selecting values from the appropriate distributions. By perturbing parameters of distributions for a site with the predicted 
Table 2. $\mathrm{CO}_{2}$ concentrations (ppm) for selected climate scenarios specified in the Special Report on Emissions Scenarios (SRES) (Nakicenovic \& Swart 2000). $\mathrm{CO}_{2}$ concentration for the baseline scenario, 1960-1990, is $334 \mathrm{ppm}$

\begin{tabular}{|c|c|c|c|c|}
\hline \multirow[t]{2}{*}{ Scenario } & \multirow[t]{2}{*}{ Key assumptions } & \multicolumn{3}{|c|}{$\mathrm{CO}_{2}$ concentration -} \\
\hline & & $2011-2030$ & $2046-2065$ & $2081-2100$ \\
\hline B1 'The sustainable world' & $\begin{array}{l}\text { Rapid change in economic structures, 'dematerialization' } \\
\text { including improved equity and environmental concern. } \\
\text { There is a global concern regarding environmental and } \\
\text { social sustainability and more effort in introducing clean } \\
\text { technologies. The global population reaches } 7 \text { billion by } 2100 \text {. }\end{array}$ & 410 & 492 & 538 \\
\hline $\begin{array}{l}\text { B2 'The world of techno- } \\
\text { logical inequalities' }\end{array}$ & $\begin{array}{l}\text { A heterogeneous society emphasising local solutions to } \\
\text { economic, social and environmental sustainability rather than } \\
\text { global solutions. Human welfare, equality and environmental } \\
\text { protection all have high priority. }\end{array}$ & 406 & 486 & 581 \\
\hline A1B 'The rich world' & $\begin{array}{l}\text { Characterised by very rapid economic growth }\left(3 \% \mathrm{yr}^{-1}\right) \text {, low } \\
\text { population growth }\left(0.27 \% \mathrm{yr}^{-1}\right) \text { and rapid introduction of new } \\
\text { and more efficient technology. Globally there is economic and } \\
\text { cultural convergence and capacity building, with a substantial } \\
\text { reduction in regional differences in per capita income. }\end{array}$ & 1 & 541 & 674 \\
\hline A2 'The separated world' & $\begin{array}{l}\text { Cultural identities separate the different regions, making the } \\
\text { world more heterogeneous and international cooperation less } \\
\text { likely. 'Family values', local traditions and high population } \\
\text { growth }\left(0.83 \% \mathrm{yr}^{-1}\right) \text { are emphasised. Less focus on economic } \\
\text { growth }\left(1.65 \% \mathrm{yr}^{-1}\right) \text { and material wealth. }\end{array}$ & 414 & 545 & 754 \\
\hline
\end{tabular}

changes of climate derived from global or regional climate models, a daily climate scenario for this site could be generated and used in conjunction with a processbased impact model for assessment of impacts. LARSWG has been tested in diverse climates and demonstrated a good performance in reproducing various weather statistics including extreme weather events (www.rothamsted.bbsrc.ac.uk/mas-models/larswg.php; Semenov et al. 1998, Semenov 2008a).

LARS-WG uses a semi-empirical distribution (SED) to approximate probability distributions of dry and wet series, daily precipitation, minimum and maximum temperatures and solar radiation. SED is defined as the cumulative probability distribution function (PDF). The number of intervals (n) used in SED is 23, which offers more accurate representation of the observed distribution compared with the 10 used in the previous ver-

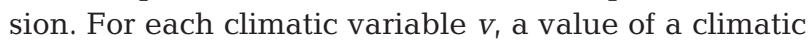
variable $v_{i}$ corresponding to the probability $\mathrm{p}_{i}$ is calculated as:

$$
v_{i}=\min \left\{v: \mathrm{P}\left(v_{\mathrm{obs}} \leq v\right) \geq \mathrm{p}_{i}\right\} i=0, \ldots, n
$$

where $\mathrm{P}()$ denotes probability based on observed data $\left\{v_{\text {obs }}\right\}$. For each climatic variable, 2 values, $p_{0}$ and $p_{n}$, are fixed as $\mathrm{p}_{0}=0$ and $\mathrm{p}_{\mathrm{n}}=1$, with corresponding values of $v_{0}=\min \left\{v_{\text {obs }}\right\}$ and $v_{\mathrm{n}}=\max \left\{v_{\mathrm{obs}}\right\}$. To approximate the extreme values of a climatic variable accurately, some $\mathrm{p}_{i}$ are assigned close to 0 for extremely low values of the variable and close to 1 for extremely high values; the remaining values of $\mathrm{p}_{i}$ are distributed evenly on the probability scale.
For precipitation, 3 values close to 1 are used: $\mathrm{p}_{\mathrm{n}-1}=$ $0.999, \mathrm{p}_{\mathrm{n}-2}=0.995$ and $\mathrm{p}_{\mathrm{n}-3}=0.985$. These values allow better approximation of events with extremely high daily precipitation that occur with very low probability, e.g. rainfall during hurricanes. Because the probability of very low daily precipitation $(<1 \mathrm{~mm})$ is typically relatively high and such low precipitation has very little effect on the output of a process-based impact model, we use only 2 values, $v_{1}=0.5 \mathrm{~mm}$ and $v_{2}=1 \mathrm{~mm}$ to approximate precipitation within the interval $[0,1]$ with the corresponding probabilities calculated as $\mathrm{p}_{i}=\mathrm{P}\left(v_{\text {obs }} \leq v_{i}\right) i=$ 1,2 . For example, the values $p_{1}=0.301$ and $p_{2}=0.416$ were estimated at Rothamsted, UK, for December.

To account for extremely long dry and wet series, 2 values close to 1 are used in SEDs for wet and dry series, $\mathrm{p}_{\mathrm{n}-1}=0.99$ and $\mathrm{p}_{\mathrm{n}-2}=0.98$. For maximum and minimum temperatures, 2 values close to 0 and 2 values close to 1 are used to account for extremely low and high temperatures, i.e. $\mathrm{p}_{2}=0.01, \mathrm{p}_{3}=0.02, \mathrm{p}_{\mathrm{n}-1}=$ 0.99 and $\mathrm{p}_{\mathrm{n}-2}=0.98$. All $\mathrm{p}_{i}$ values $(0<i<\mathrm{n})$ for radiation are distributed evenly between minimum and maximum values because of the physical constraints on minimum and maximum values of daily radiation.

In the previous version of LARS-WG, normalised residuals of maximum and minimum temperature (separate for dry and wet days) were approximated by the normal distribution with monthly means and standard deviations approximated by the Fourier series. It has been shown (Qian et al. 2004, Semenov 2008b) that for locations where temperature residuals are not normally distributed, simulation of extreme high or low tempera- 
tures could be poor compared with the observed data. For example, a frequency distribution of minimum daily temperature for January at Kuopio, Finland, for 19702000 is presented in Fig. 1A. This distribution is asymmetrical with the minimum temperature not exceeding $5^{\circ} \mathrm{C}$ and a long tail of low temperatures reaching $-40^{\circ} \mathrm{C}$. Although the mean minimum temperature was repro-
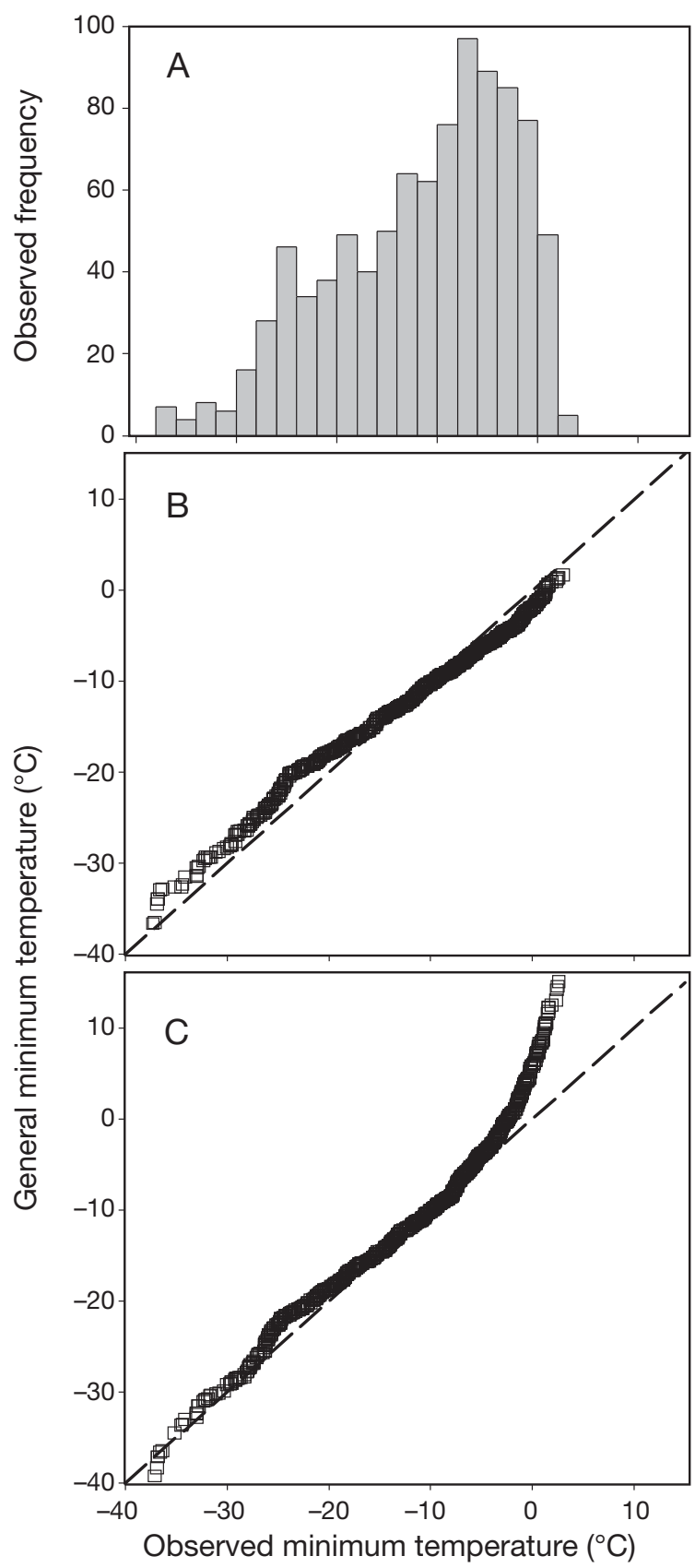

Fig. 1. Comparison between generated and observed minimum temperatures for the LARS-WG stochastic weather generator versions 5.0 and 4.0 for January at Kuopio, Finland. (A) Frequency distribution for observed daily minimum temperature (B) Q-Q plot of generated vs. observed minimum daily temperature for LARS-WG 5.0 and (C) Q-Q plot for LARS-WG 4.0 duced well, LARS-WG version 4.0 significantly overpredicted the high end of minimum temperature, with the maximum of minimum temperature reaching $15^{\circ} \mathrm{C}$ (Fig. 1C). In the LARS-WG version 5.0, the maximum and minimum temperatures for dry and wet days are approximated by semi-empirical distributions calculated for each month, with auto- and cross-correlations calculated monthly (previously, only annual auto- and crosscorrelation coefficients were used). Auto- and crosscorrelation between climatic variables was modelled as in a previous version by applying the multivariate autoregressive model to the normalised residuals. The introduction of these changes has significantly improved the simulation of extreme temperatures (Fig. 1B).

Semi-empirical distributions for climatic variables are calculated on a monthly basis by LARS-WG. Some of the variables follow an annual cycle, e.g. temperature and radiation are higher during summer in the Northern Hemisphere and lower in winter. To reproduce a smooth seasonal cycle of daily minimum or maximum temperature and daily radiation, we compute the SED for a given day by interpolating between 2 monthly SEDs. Let us assume that we need to compute SED, for a day $k$ (day of the year), $D_{k}$. We denote $k_{m}$ as a middle day of the month $m$ and assume that $\left|k-k_{m}\right| \leq 15$. To calculate $D_{k}$, we use 3 monthly distributions $D^{m-1}, D^{m}$ and $D^{m+1}$. Without losing generality, we assume that $k_{m-1}<k \leq k_{m}$. The resulting distribution for a day $k_{1} D_{k}$, is a weighted sum of the 2 distributions $D^{m-1}$ and $D^{m}$ :

$$
D_{k}=\mathrm{p}(x) D^{m-1}+(1-\mathrm{p}(x)) D^{m}
$$

where $\mathrm{p}(x)=2^{\alpha-1} x^{\alpha}, x=d / N(m), N(m)$ is a number of days in a month $m$. The parameter $\alpha$ is selected to reduce the difference between $E^{m}$, the mean value of the distribution $D^{m}$, and $\bar{E}^{m}$, the mean value for the month $m$ calculated from values generated from interpolated distributions $D_{d}$ for each day $d$ of this month, i.e.:

$$
\bar{E}^{m}=1 / N(m) \sum_{k=k_{m}-N(m) / 2}^{k_{m}+N(m) / 2} \text { mean }\left(D_{k}\right)
$$

So, $\alpha$ is selected to satisfy the following conditions

$$
\left|E^{m}-\bar{E}^{m}\right| \leq \min \left\{A_{V}, R_{V}, E^{m}\right\}
$$

where $A_{V}$ is an absolute error acceptable for a variable $V$, and $R_{V}$ is a relative error as a proportion of $E^{m}$. After computing $\bar{E}^{m}$ from Eqs. (2) and (3), an inequality Eq. (4) could be re-written as:

$$
\alpha \geq \frac{\left|\Delta_{m-}-\Delta_{m+}\right|}{4 \min \left\{A_{V}, R_{V}, E^{m}\right\}}-1
$$

where $\Delta_{m-}=E^{m}-E^{m-1}$ and $\Delta_{m+}=E^{m+1}-E^{m}$. We also limit $\alpha$ to $1 \leq \alpha \leq 4$. If $E^{m}$ is a local minimum or local maximum, i.e. $\Delta_{m-}$ and $\Delta_{m+}$ have different signs, then for all days $k$, where $\left|k-k_{m}\right| \leq 15$ we use an unmodified distribution $D^{m}$. 


\subsection{Generation of climate scenarios}

To generate climate scenarios at a site for, let's say, 2011-2030 and the SRA1B emissions scenario, the LARS-WG baseline parameters, which are calculated from observed weather for this site for the period 19601990, are adjusted by the $\Delta$-changes for 2011-2030 and the SRA1B emissions predicted by GCM for each climatic variable for the grid covering the site (using an interpolation between adjacent neighbour grids to smooth step-wise grid changes). If observed data is available for the period different from the baseline 19601990 , then an appropriate correction to $\Delta$-changes to account for this difference will be applied. Monthly predictions for each GCM from the AR4 multi-model ensemble are available for minimum and maximum temperatures (or only mean temperature for some GCMs), precipitation and radiation for the SRA1B, SRA2 and SRB1 emissions scenarios and the time periods 1960-1990, 20112030, 2046-2065 and 2081-2100. $\Delta$-changes were calculated as relative changes for precipitation and radiation and absolute changes for minimum and maximum temperatures. No adjustments for distributions of dry and wet series and temperature variability were made, because this would require daily output from the GCMs which is not readily available from the IPCC Data Centre. An example of $\Delta$-changes calculated by LARS-WG from the output of the HADCM3 global climate model for the SRA1B emissions scenario for 2046-2065 at Rothamsted, UK, is presented in Appendix 1.

Climate predictions from each GCM from the AR4 multi-model ensemble should be treated as equally probable predictions of the evolution of climate. For each GCM and each combination of the SRES emissions scenario and a future time period, $300 \mathrm{yr}$ of daily site-specific climate scenarios are generated and used by a process-based impact model to compute selected impact statistics. To present an impact statistic, computed for all GCMs from the AR4 multi-model ensemble, we combined them as a box plot. A box plot illustrate the range of uncertainty in predicting the impact associated with the uncertainty in climate predictions from the AR4 multi-model ensemble. It would be a mistake to interpret a box plot as a 'true' probability statement on the possible magnitude of the impacts. Predicted uncertainty is conditioned on the ensembles of climate models used for simulation.

\section{EXAMPLE OF IMPACT ASSESSMENT}

In a recent publication (Semenov 2009), changes in the magnitude and spatial patterns of 2 impact statistics related to wheat growth in England and Wales were analysed. The impact statistics included the probability of heat stress around flowering, which can substantially reduce final grain yield, and the drought stress index. To compute these statistics, the Sirius wheat simulation model (Jamieson et al. 1998, Jamieson \& Semenov 2000) was used to predict wheat growth for a selection of local-scale climate scenarios based on the output from the Hadley Centre regional climate model, the socalled UKCIP02 climate predictions (Hulme et al. 2002, Semenov 2007). It was shown that, despite higher temperature and lower summer precipitation predicted in the UK for the 2050s, the reduction in simulated grain yield due to drought stress is predicted to be smaller than that at present, because wheat will mature earlier in a warmer climate and avoid severe summer drought. However, the probability of heat stress around flowering that might result in considerable yield losses is predicted to increase significantly. A conclusion has been made that breeding strategies in the UK for the future climate might need to focus on wheat varieties which would be tolerant to heat stress rather than to drought.

To illustrate the use of the AR4 multi-model ensemble, we examine whether the conclusion that the probability of heat stress around flowering is likely to increase in the UK stays valid when considered across the range of AR4 multi-model climate predictions. Additionally, we analyse changes in probability of heat stress around flowering at 3 locations in southern Europe: Seville, Spain; Claremont-Ferrand, France; and Montagnano, Italy (Table 3). These locations represent

Table 3. Wheat cultivars and typical sowing dates for selected sites

\begin{tabular}{|c|c|c|c|}
\hline Site & Cultivar & Soil type & Sowing date \\
\hline Rothamsted, UK & $\begin{array}{l}\text { Mercia (obligate winter wheat with moderate to weak photoperiod } \\
\text { response; grown in the UK) }\end{array}$ & Rothamsted & $10 \mathrm{Oct}$ \\
\hline Seville, Spain & $\begin{array}{l}\text { Cartaya (bread spring wheat with weak photoperiod response; } \\
\text { grown in Spain) }\end{array}$ & Cordoba & $1 \mathrm{Jan}$ \\
\hline $\begin{array}{l}\text { Clermont-Ferrand, } \\
\text { France }\end{array}$ & $\begin{array}{l}\text { Thesee (obligate winter wheat with moderate to weak photoperiod } \\
\text { response; grown in France) }\end{array}$ & Clermont-F-C1 & $15 \mathrm{Nov}$ \\
\hline Montagnano, Italy & $\begin{array}{l}\text { Creso (durum wheat, widely cultivated in Central Italy over the past } 20 \mathrm{yr}_{\text {; }} \\
\text { very limited vernalization requirement and high sensitivity to photoperiod; } \\
\text { Motzo \& Giunta 2007) }\end{array}$ & ITAS2005 & $25 \mathrm{Nov}$ \\
\hline
\end{tabular}


diverse climates in Europe with highly variable precipitation patterns and a large range of maximum summer temperatures (Fig. 2). For example, the average annual precipitation at Seville is $524 \mathrm{~mm}$, compared to $903 \mathrm{~mm}$ at Montagnano, whilst the top figures of monthly mean maximum temperature vary from $21^{\circ} \mathrm{C}$ at Rothamsted, $\mathrm{UK}$, up to $35^{\circ} \mathrm{C}$ at Seville. Changes in monthly mean maximum temperature (Fig. 3) and precipitation (Fig. 4) as predicted by 15 GCMs used in the IPCC AR4
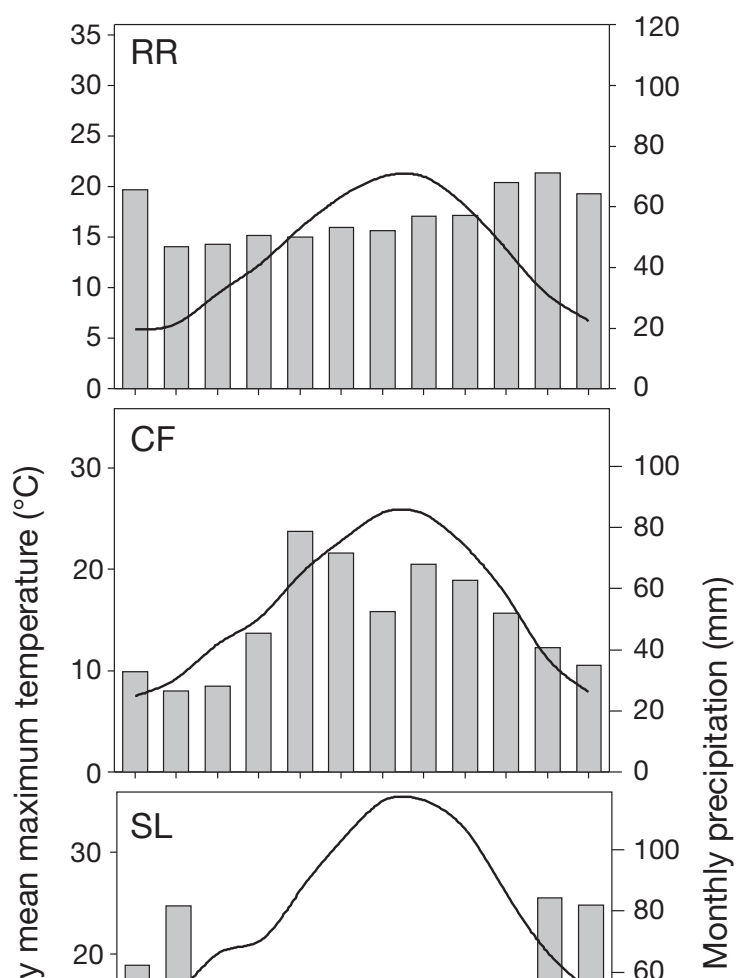
monthly mean maximum temperature (lines) at 4 locations in Europe: Rothamsted, UK (RR); Clermont-Ferrand, France (CF); Seville, Spain (SL); and Montagnano, Italy (MO)
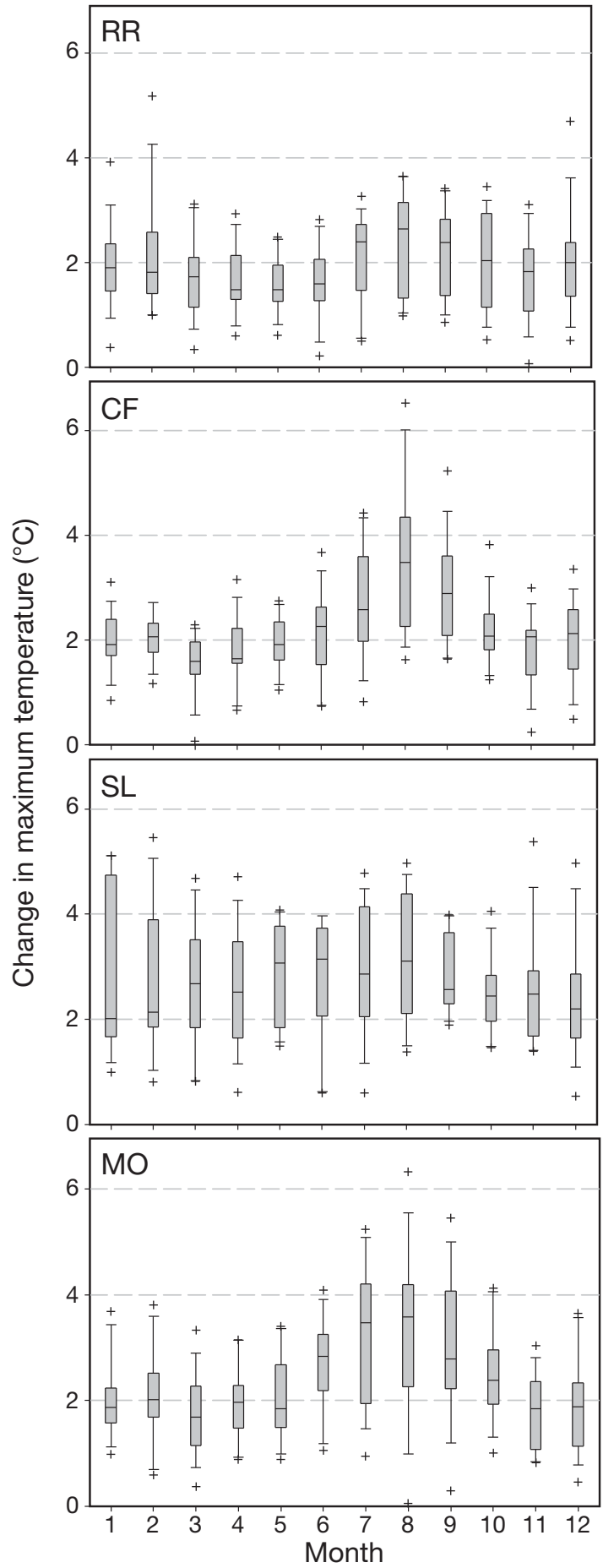

Fig. 3. Changes in monthly mean maximum temperature as predicted by 15 global climate models used in the IPCC AR4 for the SRA1B emissions scenario for 2046-2065 compared with the baseline scenario (1960-1990) at 4 European sites: Rothamsted, UK (RR); Clermont-Ferrand, France (CF); Seville, Spain (SL); and Montagnano, Italy (MO). Box boundaries indicate the 25th and 75th percentiles, the line within the box marks the median, whiskers below and above the box indicate the 10th and 90th percentiles and outliers show minimum and maximum values 


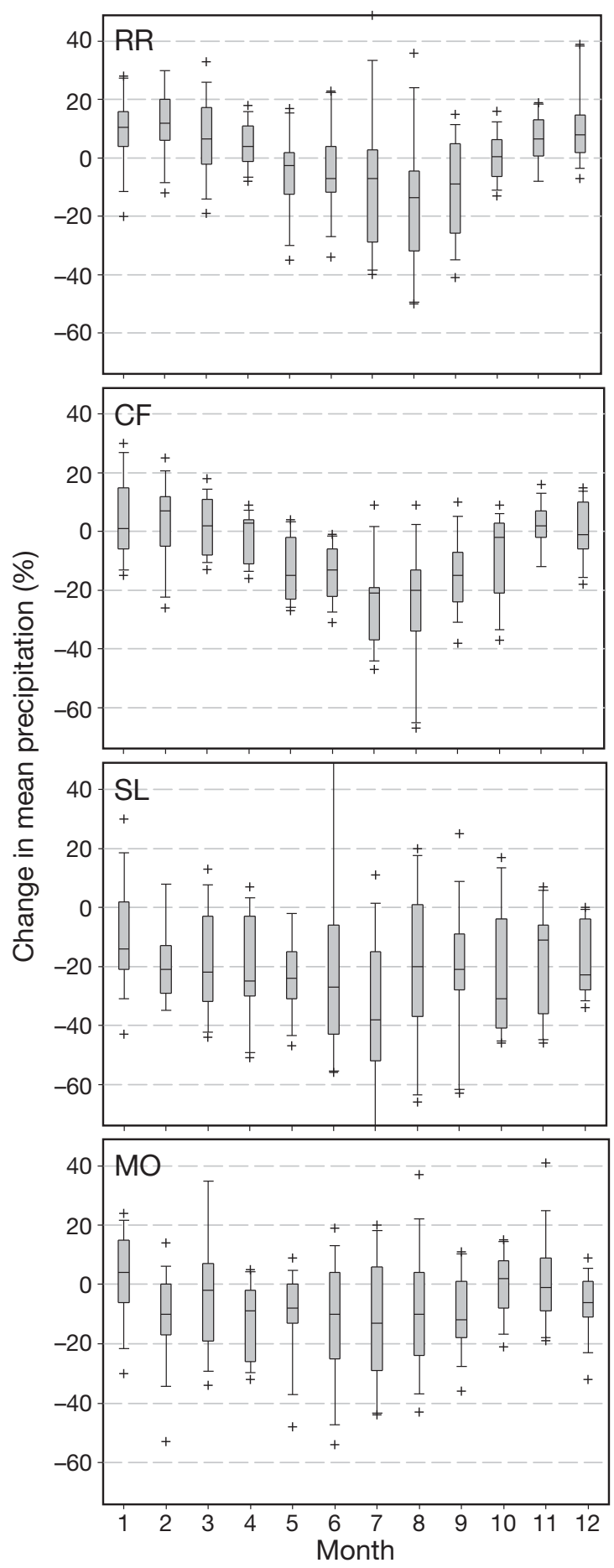

Fig. 4. As Fig. 3, but for changes in monthly mean precipitation

for the SRA1B emissions scenario for 2046-2065 compared with the baseline scenario (1960-1990) at these sites are presented as box plots.

An increase in probability of heat stress around flowering may represent a major threat for wheat production in Europe. In an experiment on the effects of $\mathrm{CO}_{2}$ and temperature on wheat yield, it was observed that high temperatures around flowering can result in a large proportion of sterile grains (Mitchell et al. 1995, Wheeler et al. 1996a, Ferris et al. 1998). Although the effect of reduced grain numbers on the final yield could be partly compensated for during grain filling by the production of larger grains, the yield losses could be still significant (Wheeler et al. 1996b). Various levels of temperature that affect the grain number were reported. We computed 2 probabilities, that the maximum temperature exceeds 27 and $30^{\circ} \mathrm{C}$ at least once during flowering. Sirius was run for wheat cultivars typically grown at the selected locations (Table 3 ). Model parameters for these cultivars were calibrated previously using observed wheat data (Wolf et al. 1996, Martre et al. 2006). Typical soils and sowing dates were selected for simulations (Table 3 ). Sirius was run for $300 \mathrm{yr}$ of synthetic daily weather for the baseline scenario representing 1960-1990, and for 2046-2065 with the SRA1B emissions scenario. It has been shown that elevated $\mathrm{CO}_{2}$ concentration increases the photosynthetic rate in wheat (C3 plant) over a wide range of radiation (Lawlor \& Mitchell 1991, Long et al. 2005). In Sirius, radiation-use efficiency is proportional to $\mathrm{CO}_{2}$ concentration and increases by $30 \%$ for a doubling in $\mathrm{CO}_{2}$ concentration (Jamieson et al. 2000, Ewert et al. 2002). $\mathrm{A} \mathrm{CO}_{2}$ concentration of $334 \mathrm{ppm}$ was used for the baseline (1960-1990), and $541 \mathrm{ppm}$ was used for the 2050s with the SRA1B emissions scenario (Table 2).

The estimated probabilities of heat stress around flowering for the baseline scenario and for the ensemble of 15 AR4 GCM climate scenarios for the SRA1B emissions in the 2050s are presented in Fig. 5. As expected, the probability of heat stress around flowering for the baseline scenario is much higher in the south of Europe than in the north. At Seville, the probabilities of exceeding 27 and $30^{\circ} \mathrm{C}$ are 0.89 and 0.43 , respectively, with corresponding probabilities at Rothamsted of only 0.11 and 0 . This may suggest that cultivars bred in southern Europe are already adapted to tolerate a high level of heat stress at flowering and have the capacity to compensate for this at the current level of heat stress. In previous work (Ferris et al. 1998), 2 parameters were identified to describe the reduction of grain number due to high temperature at flowering. These parameters are: (1) a critical temperature threshold, $T_{\text {cr }}$ beyond which the final grain number starts to decline linearly with the temperature increase; $(2)$ the slope of grain number decline $\beta$; and (3) the potential grain weight, $G_{\text {pot }}$ which determines the ability of the crop to recover the lost yield by growing larger grains (Mitchell et al. 1993, Wheeler et al. 1996b). It is likely that all 3 parameters are cultivar-specific and are different for wheat cultivars grown in southern and northern Europe. 


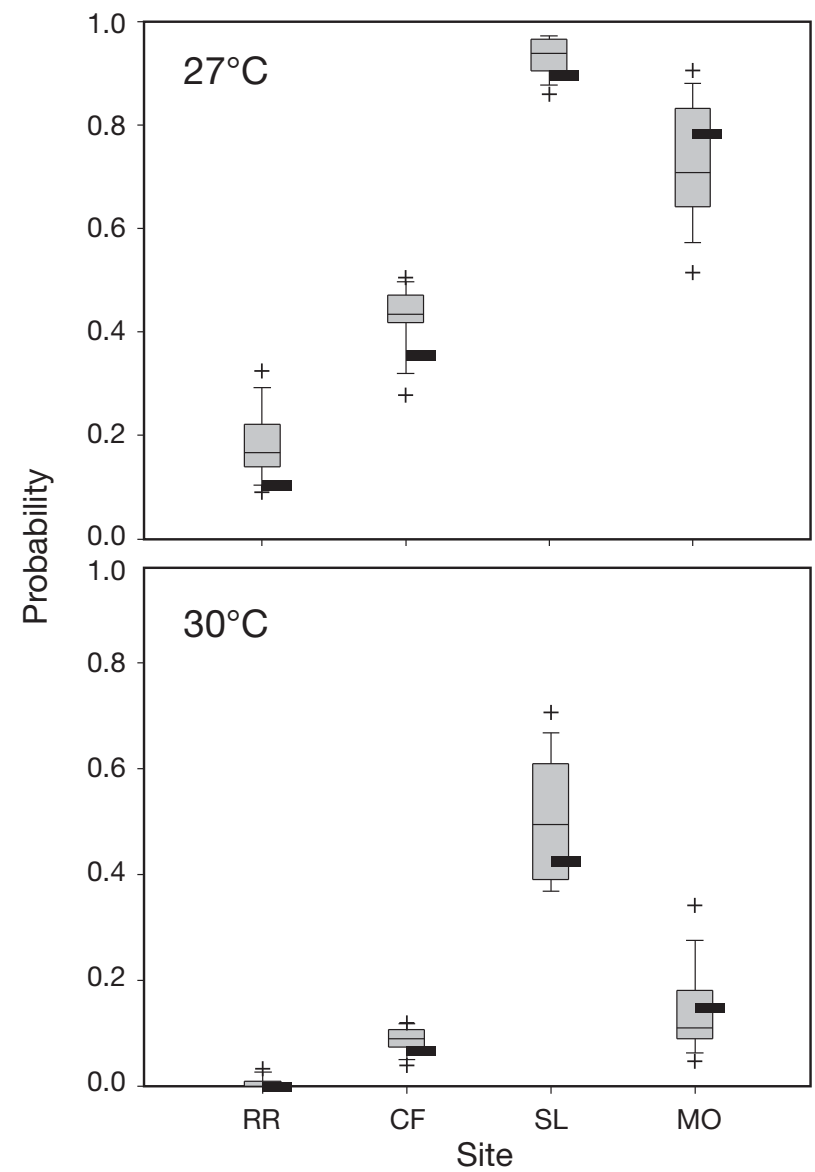

Fig. 5. Probability of the maximum daily temperature exceeding 27 and $30^{\circ} \mathrm{C}$ at least once within $5 \mathrm{~d}$ of anthesis for the baseline scenarios (thick black tick) and for the ensemble of 15 AR4 global climate model scenarios for the SRA1B emissions scenario for the 2050s presented as box plots at 4 European sites: Rothamsted, UK (RR); Clermont-Ferrand, France $(\mathrm{CF})$; Seville, Spain (SL); and Montagnano, Italy (MO). Box boundaries indicate the 25 th and 75 th percentiles, the thin line within the box marks the median, whiskers below and above the box indicate the 10th and 90th percentiles and outliers show minimum and maximum values

The probabilities of heat stress at flowering for the 2050s SRA1B emissions scenario were computed independently for each GCM from the AR4 multi-model ensemble and the results are presented as a box plot showing the median of the magnitude of change and the uncertainty of predictions (Fig. 5). It is interesting to note that, against expectations, the relative increase in the probability of heat stress around flowering between the current level and the predicted median of probabilities calculated using the AR4 climate predictions is much lower for southern locations. In Montagnano, for example, the probability is predicted to be lower for the future scenario than at present for both thresholds of 27 and $30^{\circ} \mathrm{C}$. This can be explained as follows. For northern locations, wheat reaches flower- ing much later than for southern locations. For example, at Rothamsted, average anthesis date (defined as a date when $50 \%$ of plants have flowered) is 171.0 (day of the year) compared with 141.5 at Montagnano. Because wheat development is controlled by accumulated thermal time, an increase in temperature will advance anthesis date. For the HADCM3 climate model with SRA1B emissions, the anthesis date is predicted to advance during the 2046-2065 time period by $11.6 \mathrm{~d}$ at Rothamsted and $11.8 \mathrm{~d}$ at Montagnano. This advance in anthesis date will offset temperature at anthesis by a larger value at Montagnano than at Rothamsted, because temperature follows an annual cycle and the gradient at anthesis date at Montagnano is higher than at Rothamsted (Fig. 6). Simulation results may suggest that the need for breeding for new wheat varieties, which are tolerant to heat stress around flowering, is likely to be more pressing for northern Europe.

\section{LARGE PERTURBED PHYSICS ENSEMBLES}

Recently, a systematic approach was proposed to explore the uncertainty of a single climate model to model parameterization, a so-called perturbed physics ensemble (PPE) (Murphy et al. 2004, Stainforth et al. 2005). In each experiment, model parameters were set to a range of values derived from multiple prior distributions estimated by experts, based on their knowl-

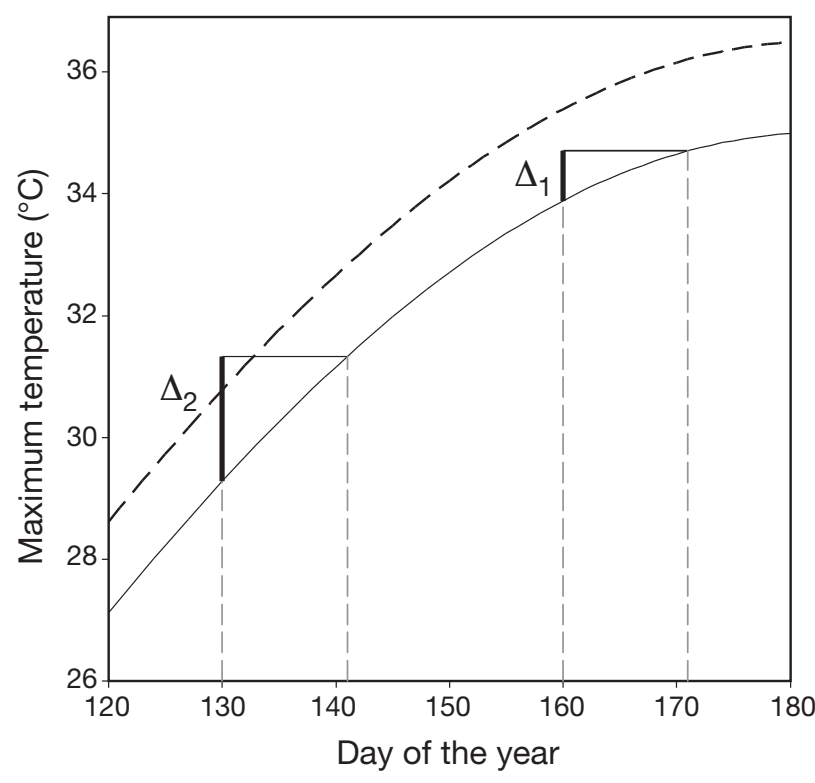

Fig. 6. Maximum temperature for the baseline (solid curve line) and future (dashed line) scenarios (a hypothetical case). The offset of temperature $\Delta_{1}$ as a result of an annual cycle for a late anthesis date (e.g. 171) is smaller than the offset of temperature $\Delta_{2}$ for an early anthesis date (e.g. 141). An increase in temperature in the future could be fully compensated by the advance in anthesis date for an early but not a late anthesis date 
edge of the relevant physical systems. The size of a PPE is considerably larger than a multi-model ensemble and could increase to hundreds of (Murphy et al. 2004) or even several thousand (Stainforth et al. 2005) individual climate experiments. In the latest climateprediction.net study (Sanderson et al. 2008), 15 parameters of a single model, HadSM3, were perturbed. Even though there was a dependency between some of the parameters and each parameter was perturbed discretely, taking only 3 possible values in most cases, the total number of individual combinations required to explore the full parameter space was enormous ( 50 000). After 'filtering' sets of predictions from HadSM3 to retain only those that remained stable in the control simulation, the number of different parameterizations was reduced to over 6000 (Sanderson et al. 2008).

For large PPEs, the approach based on the assessment of impacts for each climate model experiment becomes quickly computationally impossible, because of the demands for processor time and the storage capacity required for the impact model outputs and daily climate scenarios. An alternative method to explore uncertainty in climate predictions from very large PPEs might be needed.

One possibility is to sample a smaller subset, $\mathrm{S}_{\text {impact }}$ from a large $\mathrm{PPE}, \mathrm{S}_{\mathrm{PPE}}$, of climate experiments. If we know the size of this subset $S_{\text {impact, }}$ then the following sampling procedure can be applied. Let $N$ be the size of $\mathrm{S}_{\mathrm{PPE}}$, and $M$ be the size of a subset $\mathrm{S}_{\text {impact }}$ used for the assessment of impacts. We assume that $M \ll N$. We also assume that there is a metric $\rho$ in $\mathrm{S}_{\mathrm{PPE}}$, i.e for any 2 climate predictions $S_{1}$ and $S_{2}, \rho\left(S_{1}, S_{2}\right)$ computes a distance between climate predictions. The metric $\rho$ can be computed using a set of GCM parameters used to parameterize a climate model, or this metric could be based on one of the statistics derived from actual climate predictions, e.g. change in the global or regional temperature. The first scenario $S_{1}$ for a subset $S_{\text {impact }}$ is selected randomly from $\mathrm{S}_{\mathrm{PPE}}^{1}=\mathrm{S}_{\mathrm{PPE}}$. Then, we remove the $N / M$ climate predictions from $S_{P P E}^{1}$ with the shortest distances to $S_{1}$ as measured by $\rho_{\text {; }}$ the remaining climate predictions form the set $S_{\mathrm{PPE}}^{2}$. The second scenario $S_{2}$ for a subset $\mathrm{S}_{\text {impact }}$ is selected randomly from $\mathrm{S}_{\mathrm{PPE}}^{2}$. After removing the $N / M$ climate predictions from $\mathrm{S}_{\mathrm{PPE}}^{2}$ with the shortest distances to $S_{2}$, we construct $\mathrm{S}_{\mathrm{PPE}}^{3}$ and so on. This procedure resembles Latin hypercube sampling (McKay et al. 1979, Iman et al. 1981).

If the size the subset $S_{\text {impact }}$ is not known in advance, and is to be determined by an interactive stopping rule, e.g. sample from $\mathrm{S}_{\mathrm{PPE}}$ until some convergence criterion is met, then the Sobol sequence method can be adapted to sample climate predictions randomly, avoiding clustering and moving to finer scales as the number of samples increases (Sobol 1967).
If a probabilistic climate prediction is available for PPE, then it can be used to sample from a joint distribution of climatic variables (Rougier et al. 2009). Recently, several studies have developed methodologies to construct probabilistic climate predictions from a large PPE (Harris et al. 2006, Murphy et al. 2007, Sanderson et al. 2008, Tebaldi \& Lobell 2008, Rougier et al. 2009). Murphy et al. (2007) described a methodology, developed in the Hadley Centre, appropriate for the estimation of joint probability distribution functions of key climate variables at spatial scales of $25 \mathrm{~km}$, for use in assessments of regional climate impacts. This methodology is based on the large PPE generated using a family of parameterizations of the HadSM3 model, which comprises the HadAM3 atmospheric global climate model coupled to a simple nondynamic mixed layer ocean. A key element of this methodology is the development of a Bayesian emulator of the climate model (Rougier et al. 2009). Trained on the available predictions from the perturbed physics ensemble, the statistical emulator can provide estimates with associated errors for a range of climatic variables. These estimates are consistent with the HadSM3 climate predictions but on a much finer resolution in the model parameter space. Considering the high dimension of the HadSM3 parameter space, it is not possible to explore this space using only HadSM3 simulations (Murphy et al. 2007). When joint PDFs of changes in climate variables are constructed, they can be used to sample climate predictions for impact assessment in a more consistent way compared with sampling directly from a PPE itself. In a different study, an example of a 'non-statistical' emulator is given, based on a neural network technique applied for analysis of the multi-thousand ensemble from climateprediction.com, which can reproduce nonlinear interactions between model parameters and enabled a fuller exploration of the multidimensional model parameter space (Sanderson et al. 2008).

\section{CONCLUSIONS AND FUTURE WORK}

In the present study we outlined a methodology to assess the impact of climate change based on a multimodel ensemble of GCM predictions and to explore the range of uncertainty in impacts associated with differences between individual predictions. We treated each GCM prediction as an equally probable evolution of climate. For each climate projection, we generated a local-scale climate scenario, e.g. $300 \mathrm{yr}$ of site-specific daily weather, and computed distributions of various output variables from a crop simulation model, such as grain yield, drought stress or heat stress at flowering (only the latter is presented). These distributions characterise the uncertainty related to interannual variability in a local-scale climate scenario. 
To assess the range of uncertainty related to differences in climate predictions from the AR4 multi-model ensemble, we computed an impact index for each GCM, e.g. the probability of heat stress at flowering as predicted by HadCM3. Values of this impact index calculated for all GCMs were then combined in a box plot. This final graph shows the range of uncertainty in prediction of an impact index resulting from limitations in our current understanding of the climate system as modelled by GCMs. We have to note that this summary box plot should not be interpreted as a probability statement of what might happen, but only as an uncertainty range. It has been pointed out by Rougier (2007) that making a probabilistic prediction about future climate requires explicit specification of a probability distribution for climate itself.

GCMs and impact models are undergoing continuous development and improvement; they are methodically tested against observed data (the process called model validation), which increases our confidence in the models' predictions and reduces the level of uncertainty (Jamieson et al. 2000, Ewert et al. 2002, Palmer et al. 2005).

LARS-WG version 5 incorporates climate predictions from the AR4 multi-model ensemble. Nevertheless, to generate local-scale climate scenario, the user needs observed daily weather for a site for 20 to 30 yr to estimate the LARS-WG site parameters. This step can be made redundant if a data set of site parameters for a region of interest is prepared in advance. Recently, a data set, 'ELPIS', of the site parameters for western and central Europe has been developed. Site parameters were estimated for daily precipitation, minimum and maximum temperatures and radiation for a $25 \mathrm{~km}$ grid across Europe using observed daily weather for the period 1982-2008. ELPIS should soon be made available to the user community.

Regional climate models (RCM) have shown a substantial improvement in modelling spatial weather patterns compared with GCMs due to much finer spatial resolution (25 to $50 \mathrm{~km}$ ) (Beniston et al. 2007, Salon et al. 2008). Currently, in the EU-FW6 ENSEMBLES project (Jacob et al. 2007), 14 regional climate models were used to downscale GCM predictions for Europe with the spatial resolution of $25 \mathrm{~km}$ (and/or $50 \mathrm{~km}$ ) and for the period 1951-2050 (or 1951-2100 for some RCMs). The daily outputs from the ENSEMBLES RCMs have been recently made available online from the project website (ensemblesrt3.dmi.dk). We are planning to incorporate all RCM predictions from the EU-FW6 ENSEMBLES project into the next release of LARS-WG. This will provide much better spatial resolution of predicted climatic changes for Europe and will allow incorporation of changes in climatic variability as well as changes in mean climate into local-scale climate scenarios.
Acknowledgements. Many thanks to S. Welham, A. Milne and 2 anonymous reviewers for their comments. P.S. was supported by a grant (BB/F021038/1) from the Biotechnology and Biological Sciences Research Council of the UK (BBSRC). We acknowledge the Model and Data Group (M\&D) at the MaxPlanck-Institute for Meteorology, with funding from the Federal Ministry for Education and Research and by the German Climate Computing Centre (DKRZ) for providing access to data and technical assistance. Rothamsted Research receives grant-aided support from BBSRC.

\section{LITERATURE CITED}

Bardossy A (1997) Downscaling from GCMs to local climate through stochastic linkages. J Environ Manage 49:7-17

Barrow EM, Semenov MA (1995) Climate change scenarios with high spatial and temporal resolution for agricultural applications. Forestry 68:349-360

Barrow E, Hulme M, Semenov MA (1996) Effect of using different methods in the construction of climate change scenarios: examples from Europe. Clim Res 7:195-211

> Beniston M, Stephenson DB, Christensen OB, Ferro CAT and others (2007) Future extreme events in European climate: an exploration of regional climate model projections. Clim Change 81:71-95

Collins WD, Hack JJ, Boville BA, Rasch PJ and others (2004) Description of the NCAR Community Atmosphere Model (CAM3.0). Technical Note TN-464+STR, National Center for Atmospheric Research, Boulder, CO

Covey C, AchutaRao KM, Cubasch U, Jones P and others (2003) An overview of results from the Coupled Model Intercomparison Project. Global Planet Change 37:103-133

CSMD (Climate System Modeling Division) (2005) An introduction to the first general operational climate model at the National Climate Center. Advances in Climate System Modeling 1, National Climate Center, China Meteorological Administration

> Déqué M, Dreveton C, Braun A, Cariolle D (1994) The ARPEGE/IFS atmosphere model: a contribution to the French community climate modeling. Clim Dyn 10:249-266

Déqué M, Rowell DP, Luthi D, Giorgi F and others (2007) An intercomparison of regional climate simulations for Europe: assessing uncertainties in model projections. Clim Change 81:53-70

Doblas-Reyes FJ, Hagedorn R, Palmer TN (2006) Developments in dynamical seasonal forecasting relevant to agricultural management. Clim Res 33:19-26

Dubrovsky M, Buchtele J, Zalud Z (2004) High-frequency and low-frequency variability in stochastic daily weather generator and its effect on agricultural and hydrologic modelling. Clim Change 63:145-179

Evans N, Baierl A, Semenov MA, Gladders P, Fitt BDL (2008) Range and severity of a plant disease increased by global warming. J R Soc Interface 5:525-531

Ewert F, Rodriguez D, Jamieson P, Semenov MA and others (2002) Effects of elevated $\mathrm{CO}_{2}$ and drought on wheat: testing crop simulation models for different experimental and climatic conditions. Agric Ecosyst Environ 93:249-266

Ferris R, Ellis RH, Wheeler TR, Hadley P (1998) Effect of high temperature stress at anthesis on grain yield and biomass of field-grown crops of wheat. Ann Bot 82:631-639

Galin VY, Volodin EM, Smyshliaev SP (2003) Atmospheric general circulation model of INM RAS with ozone dynamics. Russ Meteorol Hydrol 5:13-22

GFDL-GAMDT (GFDL Global Atmospheric Model Development Team) (2004) The new GFDL global atmosphere and 
land model AM2-LM2: evaluation with prescribed SST simulations. J Clim 17:4641-4673

Giorgi F, Mearns LO (1991) Approaches to the simulation of regional climate change: a review. Rev Geophys 29: 191-216

> Gordon C, Cooper C, Senior CA, Banks H and others (2000) The simulation of SST, sea ice extents and ocean heat transports in a version of the Hadley Centre coupled model without flux adjustments. Clim Dyn 16:147-168

Gordon HB, Rotstayn LD, McGregor JL, Dix MR and others (2002) The CSIRO Mk3 climate system model. CSIRO Atmospheric Research, Aspendale

Harris GR, Sexton DMH, Booth BBB, Collins M, Murphy JM, Webb MJ (2006) Frequency distributions of transient regional climate change from perturbed physics ensembles of general circulation model simulations. Clim Dyn $27: 357-375$

- Hewitson BC, Crane RG (1996) Climate downscaling: techniques and application. Clim Res 7:85-95

> Hourdin F, Musat I, Bony S, Braconnot P and others (2006) The LMDZ4 general circulation model: climate performance and sensitivity to parameterized physics with emphasis on tropical convection. Clim Dyn 27:787-813

Huebener $\mathrm{H}$, Cubasch U, Langematz U, Spangehl T, Niehorster F, Fast I, Kunze M (2007) Ensemble climate simulations using a fully coupled ocean-tropospherestratosphere general circulation model. Philos Trans R Soc A 365:2089-2101

Hulme M, Jenkins GJ, Lu X, Turnpenny JR and others (2002) Climate change scenarios for the United Kingdom: the UKCIP02 scientific report. Tyndall Centre for Climate Change Research and School of Environmental Sciences, University of East Anglia, Norwich

Iman RL, Helton JC, Campbell JE (1981) An approach to sensitivity analysis of computer models. I. Introduction, input variable selection and preliminary variable assessment. J Qual Technol 13:174-183

> Jacob D, Barring L, Christensen OB, Christensen JH and others (2007) An inter-comparison of regional climate models for Europe: model performance in present-day climate. Clim Change 81:31-52

Jamieson PD, Semenov MA (2000) Modelling nitrogen uptake and redistribution in wheat. Field Crops Res 68:21-29

Jamieson PD, Semenov MA, Brooking IR, Francis GS (1998) Sirius: a mechanistic model of wheat response to environmental variation. Eur J Agron 8:161-179

Jamieson PD, Berntsen J, Ewert F, Kimball BA and others (2000) Modelling $\mathrm{CO}_{2}$ effects on wheat with varying nitrogen supplies. Agric Ecosyst Environ 82:27-37

K-1 Model Developers (2004) K-1 Coupled Model (MIROC) description. Center for Climate System Research, University of Tokyo

Kiehl JT, Gent PR (2004) The Community Climate System Model, version 2. J Clim 17:3666-3682

Kiehl JT, Hack JJ, Bonan GB, Boville BA, Williamson DL, Rasch PJ (1998) The National Center for Atmospheric Research Community Climate Model: CCM3. J Clim 11:1131-1149

Lawlor DW, Mitchell RAC (1991) The effects of increasing $\mathrm{CO}_{2}$ on crop photosynthesis and productivity: a review of field studies. Plant Cell Environ 14:807-818

Long SP, Ainsworth EA, Leakey ADB, Morgan PB (2005) Global food insecurity. Treatment of major food crops with elevated carbon dioxide or ozone under large-scale fully open-air conditions suggests recent models may have overestimated future yields. Philos Trans R Soc B 360:2011-2020

> Martin GM, Ringer MA, Pope VD, Jones A, Dearden C, Hinton TJ (2006) The physical properties of the atmosphere in the new Hadley Centre Global Environmental Model (HadGEM1). I. model description and global climatology. J Clim 19:1274-1301

Martre P, Jamieson PD, Semenov MA, Zyskowski RF, Porter JR, Triboi E (2006) Modelling protein content and composition in relation to crop nitrogen dynamics for wheat. Eur J Agron 25:138-154

Mavromatis T, Hansen JW (2001) Interannual variability characteristics and simulated crop response of four stochastic weather generators. Agric For Meteorol 109:283-296

McFarlane NA, Boer GJ, Blanchet JP, Lazare M (1992) The Canadian Climate Centre second-generation general circulation model and its equilibrium climate. J Clim 5:1013-1044

- McKay MD, Beckman RJ, Conover WJ (1979) A comparison of three methods for selecting values of input variables in the analysis of output from a computer code. Technometrics 21:239-245

> Mearns LO, Rosenzweig C, Goldberg R (1997) Mean and variance change in climate scenarios: methods, agricultural applications, and measures of uncertainty. Clim Change 35:367-396

Mearns LO, Bogardi I, Giorgi F, Matyasovskey I, Paleski M (1999) Comparison of climate change scenarios generated from regional climate model experiments and statistical downscaling. J Geophys Res 104:6603-6621

Mitchell RAC, Mitchell VJ, Driscoll SP, Franklin J, Lawlor DW (1993) Effects of increased $\mathrm{CO}_{2}$ concentration and temperature on growth and yield of winter wheat at two levels of nitrogen application. Plant Cell Environ 16:521-529

> Mitchell RAC, Lawlor DW, Mitchell VJ, Gibbard CL, White EM, Porter JR (1995) Effects of elevated $\mathrm{CO}_{2}$ concentration and increased temperature on winter wheat: test of ARCWHEAT1 simulation model. Plant Cell Environ 18: 736-748

Moot DJ, Henderson AL, Porter JR, Semenov MA (1996) Temperature, $\mathrm{CO}_{2}$ and the growth and development of wheat: changes in the mean and variability of growing conditions. Clim Change 33:351-368

Motzo R, Giunta F (2007) The effect of breeding on the phenology of Italian durum wheats: from landraces to modern cultivars. Eur J Agron 26:462-470

Murphy J (1999) An evaluation of statistical and dynamical techniques for downscaling local climate. J Clim 12: 2256-2284

> Murphy JM, Sexton DMH, Barnett DN, Jones GS, Webb MJ, Collins M, Stainforth DA (2004) Quantification of modelling uncertainties in a large ensemble of climate change simulations. Nature 430:768-772

Murphy JM, Booth BBB, Collins M, Harris GR, Sexton DMH, Webb MJ (2007) A methodology for probabilistic predictions of regional climate change from perturbed physics ensembles. PhilosTrans R Soc A 365:1993-2028

Nakicenovic N, Swart R (eds) (2000) Emissions scenarios. Special Report of the Intergovernmental Panel on Climate Change. Cambridge University Press, Cambridge

Otto-Bliesner BL, Schneider R, Brady EC, Kucera M and others (2009) A comparison of PMIP2 model simulations and the MARGO proxy reconstruction for tropical sea surface temperatures at last glacial maximum. Clim Dyn 32:799-815

Palmer TN, Alessandri A, Andersen U, Cantelaube P and others (2004) Development of a European multimodel ensemble system for seasonal-to-interannual prediction (DEMETER). Bull Am Meteorol Soc 85:853-888

> Palmer TN, Doblas-Reyes FJ, Hagedorn R, Weisheimer A (2005) Probabilistic prediction of climate using multimodel ensembles: from basics to applications. Philos Trans R Soc B 360:1991-1998 
Palmer TN, Doblas-Reyes FJ, Weisheimer A, Rodwell MJ (2008) Toward seamless prediction: calibration of climate change projections using seasonal forecasts. Bull Am Meteorol Soc 89:459-470

Pope VD, Gallani ML, Rowntree PR, Stratton RA (2000) The impact of new physical parametrizations in the Hadley Centre climate model: HadAM3. Clim Dyn 16:123-146

Porter JR, Semenov MA (1999) Climate variability and crop yields in Europe. Nature 400:724

Porter JR, Semenov MA (2005) Crop responses to climatic variation. Philos Trans R Soc B 360:2021-2035

Qian BD, Gameda S, Hayhoe H, De Jong R, Bootsma A (2004) Comparison of LARS-WG and AAFC-WG stochastic weather generators for diverse Canadian climates. Clim Res 26:175-191

Racsko P, Szeidl L, Semenov M (1991) A serial approach to local stochastic weather models. Ecol Model 57:27-41

Ramstein G, Kageyama M, Guiot J, Wu H, Hely C, Krinner G, Brewer S (2007) How cold was Europe at the Last Glacial Maximum? A synthesis of the progress achieved since the first PMIP model-data comparison. Clim Past 3:331-339

Richardson CW, Wright DA (1984) WGEN: a model for generating daily weather variables. Report No. ARS-8, US Department of Agriculture, Agricultural Research Service

Ringer MA, Martin GM, Greeves CZ, Hinton TJ and others (2006) The physical properties of the atmosphere in the new Hadley Centre Global Environmental Model (HadGEM1). Part II: aspects of variability and regional climate. J Clim 19: $1302-1326$

Roeckner E, Arpe $\mathrm{K}$, Bengtsson L, Christoph $\mathrm{M}$ and others (1996) The atmospheric general circulation model ECHAM4: model description and simulation of present-day climate. Max-Planck-Institut für Meteorologie, Hamburg

Rougier J (2007) Probabilistic inference for future climate using an ensemble of climate model evaluations. Clim Change 81:247-264

Rougier J, Sexton DMH, Murphy JM, Stainforth D (2009) Analysing the climate sensitivity of the HadSM3 climate model using ensembles from different but related experiments. J Clim 22:3540-3557

Russell GL, Miller JR, Rind D (1995) A coupled atmosphereocean model for transient climate change studies. AtmosOcean 33:683-730

Salon S, Cossarini G, Libralato S, Gao X, Solidoro S, Giorgi F (2008) Downscaling experiment for the Venice lagoon. I. Validation of the present-day precipitation climatology. Clim Res 38:31-41

Sanderson BM, Knutti R, Aina T, Christensen C and others (2008) Constraints on model response to greenhouse gas forcing and the role of subgrid-scale processes. J Clim 21: $2384-2400$

Semenov MA (2007) Development of high-resolution UKCIP02-based climate change scenarios in the UK. Agric For Meteorol 144:127-138

Semenov MA (2008a) Extreme impacts of climate change on wheat in England and Wales. Asp Appl Biol 88:37-38

Semenov MA (2008b) Simulation of extreme weather events by a stochastic weather generator. Clim Res 35:203-212

Semenov MA (2009) Impacts of climate change on wheat in England and Wales. J R Soc Interface 6:343-350
Semenov MA, Barrow EM (1997) Use of a stochastic weather generator in the development of climate change scenarios. Clim Change 35:397-414

> Semenov MA, Brooks RJ (1999) Spatial interpolation of the LARS-WG stochastic weather generator in Great Britain. Clim Res 11:137-148

> Semenov MA, Halford NG (2009) Identifying target traits and molecular mechanisms for wheat breeding under a changing climate. J Exp Bot 60:2791-2804

Semenov MA, Porter JR (1995) Climatic variability and the modeling of crop yields. Agric For Meteorol 73:265-283

Semenov MA, Brooks RJ, Barrow EM, Richardson CW (1998) Comparison of the WGEN and LARS-WG stochastic weather generators in diverse climates. Clim Res 10:95-107

Sobol IM (1967) On the distribution of points in a cube and the approximate evaluation of integrals. USSR Comput Math Math Phys 7:86-112

Solomon S, Qin D, Manning M, Marquis M and others (eds) (2007) Climate Change 2007: the physical science basis. Contribution of Working Group I to the Fourth Assessment Report of the Intergovermental Panel on Climate Change. Cambridge University Press, Cambridge

Stainforth DA, Aina T, Christensen C, Collins M and others (2005) Uncertainty in predictions of the climate response to rising levels of greenhouse gases. Nature 433:403-406

Tebaldi C, Lobell DB (2008) Towards probabilistic projections of climate change impacts on global crop yields. Geophys Res Lett 35:L08705, doi:10.1029/2008GLO33423

> Trigo RM, Palutikof JP (2001) Precipitation scenarios over Iberia: a comparison between direct GCM output and different downscaling techniques. J Clim 14:4422-4446

> Wang B, Wan H, Ji Z, Zhang X, Yu R, Yu Y, Liu H (2004) Design of a new dynamical core for global atmospheric models based on some efficient numerical methods. Sci China Ser A Math Phys Astron 47:4-21

- Wheeler TR, Batts GR, Ellis RH, Hadley P, Morison JIL (1996a) Growth and yield of winter wheat (Triticum aestivum) crops in response to $\mathrm{CO}_{2}$ and temperature. J Agric Sci 127: $37-48$

Wheeler TR, Hong TD, Ellis RH, Batts GR, Morison JIL, Hadley P (1996b) The duration and rate of grain growth, and harvest index, of wheat (Triticum aestivum L.) in response to temperature and $\mathrm{CO}_{2}$. J Exp Bot 47:623-630

Wheeler TR, Craufurd PQ, Ellis RH, Porter JR, Prasad PVV (2000) Temperature variability and the yield of annual crops. Agric Ecosyst Environ 82:159-167

Wilby RL, Wigley TML, Conway D, Jones PD, Hewiston BC, Main J, Wilks DS (1998) Statistical downscaling of general circulation model output: a comparison of methods. Water Resour Res 34:2995-3008

Wilks DS (1992) Adapting stochastic weather generation algorithms for climate changes studies. Clim Change 22: $67-84$

Wilks DS, Wilby RL (1999) The weather generation game: a review of stochastic weather models. Prog Phys Geogr 23: 329-357

Wolf J, Evans LG, Semenov MA, Eckersten H, Iglesias A (1996) Comparison of wheat simulation models under climate change. I. Model calibration and sensitivity analyses. Clim Res 7:253-270 
Appendix 1. A scenario file calculated by the LARS-WG stochastic weather generator for the HADCM3 global climate model for the SRA1B emissions scenario for the time period 2046-2065 at Rothamsted, UK

\begin{tabular}{|c|c|c|c|c|c|c|c|c|}
\hline // & \multicolumn{8}{|c|}{ LARS-WG5.11 } \\
\hline // & \multicolumn{8}{|c|}{ Columns are: } \\
\hline // & [1] & \multicolumn{7}{|c|}{ month } \\
\hline // & {$[2]$} & \multicolumn{7}{|c|}{ relative change in monthly mean rainfall } \\
\hline // & [3] & \multicolumn{7}{|c|}{ relative change in duration of wet spell } \\
\hline // & [4] & \multicolumn{7}{|c|}{ relative change in duration of dry spell } \\
\hline // & [5] & \multicolumn{7}{|c|}{ absolute changes in monthly mean min temperature } \\
\hline // & [6] & \multicolumn{7}{|c|}{ absolute changes in monthly mean max temperature } \\
\hline // & [7] & \multicolumn{7}{|c|}{ relative changes in daily temperature variability } \\
\hline // & [8] & \multicolumn{7}{|c|}{ relative changes in mean monthly radiation } \\
\hline \multicolumn{9}{|c|}{ 1 } \\
\hline \multicolumn{9}{|c|}{ LARS-WG5.11 } \\
\hline \multicolumn{9}{|c|}{ [NAME] } \\
\hline \multirow{2}{*}{\multicolumn{9}{|c|}{$\begin{array}{l}\text { RR_RR_HADCM3_SRA1B_2046-2065 } \\
\text { [BASELINE] }\end{array}$}} \\
\hline & & & & & & & & \\
\hline \multicolumn{9}{|c|}{1975} \\
\hline \multicolumn{9}{|c|}{ [FUTURE] } \\
\hline \multicolumn{9}{|c|}{2055} \\
\hline \multicolumn{9}{|c|}{ [GCM PREDICTIONS] } \\
\hline & Jan & 1.14 & 1.00 & 1.00 & 1.80 & 1.80 & 1.00 & 0.95 \\
\hline & Feb & 1.30 & 1.00 & 1.00 & 2.11 & 2.11 & 1.00 & 0.99 \\
\hline & Mar & 1.33 & 1.00 & 1.00 & 1.80 & 1.80 & 1.00 & 0.97 \\
\hline & Apr & 0.99 & 1.00 & 1.00 & 0.91 & 0.91 & 1.00 & 1.02 \\
\hline & May & 0.75 & 1.00 & 1.00 & 2.13 & 2.13 & 1.00 & 1.11 \\
\hline & Jun & 0.90 & 1.00 & 1.00 & 2.05 & 2.05 & 1.00 & 1.09 \\
\hline & Jul & 0.63 & 1.00 & 1.00 & 2.39 & 2.39 & 1.00 & 1.08 \\
\hline & Aug & 0.57 & 1.00 & 1.00 & 3.63 & 3.63 & 1.00 & 1.13 \\
\hline & Sep & 0.75 & 1.00 & 1.00 & 3.34 & 3.34 & 1.00 & 1.15 \\
\hline & Oct & 1.16 & 1.00 & 1.00 & 3.00 & 3.00 & 1.00 & 1.05 \\
\hline & Nov & 1.19 & 1.00 & 1.00 & 1.98 & 1.98 & 1.00 & 1.07 \\
\hline & Dec & 1.02 & 1.00 & 1.00 & 1.46 & 1.46 & 1.00 & 1.04 \\
\hline
\end{tabular}

Editorial responsibility: Balaji Rajagopalan, Boulder, Colorado, USA
Submitted: June 5, 2009; Accepted: November 13, 2009 Proofs received from author(s): January 13, 2010 